\title{
Constraints being Faced by the KCC Farmers in Bikaner District of Rajasthan
}

\author{
Amit Kumar Keshri* \\ Department of Agricultural Extension, Krishi Vigyan Kendra, Kaushambi, India \\ *Corresponding author
}

\section{A B S T R A C T}

Keywords

KCC holders,

Constraints

Article Info

Accepted:

15 January 2021

Available Online:

10 February 2021
The present investigation was conducted in Bikaner district of Rajasthan. Tehsil Bikaner was selected due to its maximum population. Ten villages have been included for the investigation based on their maximum population. One hundred fifty farmers $(75 \mathrm{KCC}$ holders and 75 Non- KCC holders) were selected from each of the chosen villages through probability proportionate procedure (in case of KCC holders, similar number of NonKCC holders from each village). Data were collected by personal interview method. To arrive at specific inferences, various statistical measures viz., ' $z$ ' test, ' $t$ ' test and Spearman's rank correlation test were used. Among four categories of constraints, general constraints were perceived with highest intensity followed by economical, technical and social constraints.

\section{Introduction}

Kisan Credit Card (KCC) was started by the GOI in consultation with the RBI and NABARD in 1998-99.

This was implemented throughout the country by public sector commercial banks, RRBs and cooperative banks.

The target groups of beneficiaries for KCCs are all categories of farmers, vulnerable groups like defaulters-farmers, oral lessees, tenant farmers, share croppers and others who have been left outside the fold of KCC Schemes for any reasons etc. The present $\mathrm{KCC}$ scheme aimed at providing adequate and timely support from the banking system to the farmers for the short term cultivation requirements for the cultivation of different crops. Limited studies have been conducted by the researchers in order to ascertain its impact on its beneficiaries. With this background, the present study, entitled "Impact of Kisan Credit Card (KCC) on socio-economic status of the farmers of Bikaner District, Rajasthan" was undertaken along with the specific objective given here under. 


\section{Materials and Methods}

The present study was conducted purposely in Bikaner district of Rajasthan as the district has need for the study because as till now no study has been designed and undertaken in this area.. Tehsil Bikaner appears to be at $1^{\text {st }}$ and foremost place as far as its total population $(2,363,937)$ is concerned. This was followed by other seven Tehsils. Therefore, Tehsil Bikaner was being proposed to be included and selected for the present study with the impression that desired representative sample (KCC farmers) would be available to the student researcher. The villages were arranged in descending order based on total population, first ten villages based on highest population were drawn up and included for the investigation. The KCC holders were those for the investigation who were benefited under the scheme during the period of 2003-04 to 200809.

Prior to actual selection of targeted respondents, a comprehensive list of $\mathrm{KCC}$ holders and Non- KCC holders was prepared by the researcher for this purpose. A total size of sample that constituted was 150 of respondents (75 beneficiaries and 75 non beneficiaries). Interview schedule was prepared to measure the level of constraints being faced by the KCC farmers. The degree of severity of constraints was measured on three points' continuum, these points were most severe, severe, and not severe with their scores 3,2 and 1 respectively.

\section{Results and Discussion}

\section{Constraints being faced by the KCC farmers}

Adoption of a scheme or a new technology depends on various factors, which may either accelerate or retard its adoption, it is important on the part of extension functionaries to identify such factors so as to make the dissemination of technologies in line with the farmers' perception and need. Considering the crucial importance of constraints which hinder the adoption of KCC scheme among the farmers in the study area, the researcher made efforts and collected data in this regard and the data and present in following uses.

Various constraints with their respective intensities have been presented under the KCC following tables $1-5$.

\section{Level of technical constraints perceived by KCC farmers}

The data incorporated in table 1 reveals that "lack of knowledge about banking system" and "Delay in loaning" were the most severe constraints expressed by all of the KCC farmers which were assigned first and second rank with 95.6 and 84.0 MPS respectively.

Lack of motivation from officials, lack of extension contacts and insufficient credit limit were next three severe constraints ranked as III, IV and V with their respective MPS 79.6, 72 and 64. The study recommended constraints related to banking system, delay in loaning them go for KCC, lack of motivation, lack of extension contacts and insufficient credit limit must be minimized.

\section{Level of economical constraints perceived by KCC farmers}

The data incorporated in table 2 reveal that "Fragmentation of landholdings" and "Depend upon the money leader irrespective of their high interest charges" were the most severe constraints expressed by KCC farmers which were assigned first and second rank with MPS 96.9 and 88.9 respectively. Table also shows that "High and exorbitant interest rate" was perceived to be less severe constraint perceived by farmers, as it was placed at the 
last rank with its total MPS 49.8. It is strongly recommended that cooperative farming be encouraged, money leader must be removed and certainty of repaying of credits be ensured in the study area.

\section{Level of social constraints perceived by KCC farmers}

A perusal of data incorporated in table 3 reveal that "illiteracy in the society", "Poor contacts with officers" and "Traditional society" were expressed as the most severe constraints felt by the respondents which were placed at 1,2, and 3 ranks with their MPS $92.4,83.6$, and 76.4 respectively.

"The loan does not meet their real credit need" and "lack of support of family members" were less severe constraints perceived by the respondents and ranked 4, and 5 with their MPS 59.6 and 36.4 respectively. Study recommended that farmers should be trained about the scheme so they can change the mindset-up of illiterate, traditional society and they can establish strong contacts with officers.

\section{Level of miscellaneous constraints perceived by $\mathrm{KCC}$ farmers}

A perusal of data incorporated in Table 4 recommended that the following most severe constraints perceived by the KCC farmers under scheme must be looked in to seriously. (I) lengthy paper work, (II) Illiteracy of farmers leads to various difficulties in understanding of KCC scheme, (III) Unavailability of communication network, (IV) Upgraded to an ATM kisan card.

"Difficulty in opening bank account" and "Villages are not getting any bank branch in near by area" were less severe constraints perceived by the respondents and ranked V, and VI with 67.6 and 58.2 MPS, respectively by them.

\section{Level of overall constraints perceived by KCC farmers}

To get an overview of the level of constraints, the constraints were divided into two categories. These categories were formed on the basis of calculated mean per cent score and rank given to the constraints by the respondents. The results of the same have been given in Table 5 .

Perusal data in table 5 reveal that majority of respondents 80.2 MPS were having first rank in general constraints, while 74.7 MPS were have second rank in economical constraints. Regarding of technical constraints the proportion of respondents recorded with 70.4 MPS were have third rank.

Table.1 Level of technical constraints perceived by KCC farmers

\begin{tabular}{|c|c|c|c|}
\multicolumn{2}{|c}{} & \multicolumn{2}{c|}{$\mathrm{N}=75$} \\
\hline S. No. & Aspect & MPS & Rank \\
\hline $\mathbf{1 .}$ & Lack of knowledge about banking system & 95.6 & I \\
\hline $\mathbf{2 .}$ & Lack of awareness about the benefits of scheme & 48.0 & VII \\
\hline $\mathbf{3 .}$ & Lack of motivation from officials & 79.6 & III \\
\hline $\mathbf{4}$. & Lack of media exposure & 63.6 & VI \\
\hline $\mathbf{5 .}$ & Lack of extension contacts & 72.0 & IV \\
\hline $\mathbf{6 .}$ & Insufficient credit limit & 64.0 & V \\
\hline $\mathbf{7 .}$ & Delay in loaning & & II \\
\hline
\end{tabular}


Table.2 Aspects wise economical constraints perceived by KCC farmers

\begin{tabular}{|c|c|c|c|}
\hline \multicolumn{2}{|c|}{ N $=75$} \\
\hline S. No. & Aspect & MPS & Rank \\
\hline $\mathbf{1 .}$ & High and exorbitant interest rate & 49.8 & VI \\
\hline $\mathbf{2 .}$ & Uncertainty of repaying & 75.6 & III \\
\hline $\mathbf{3 .}$ & Fragmentation of land holdings & 96.9 & I \\
\hline $\mathbf{4}$ & Fear of being defaulter & 64.4 & V \\
\hline $\mathbf{5 .}$ & Depend upon the money leader irrespective of their high interest charges & 88.9 & II \\
\hline $\mathbf{6 .}$ & Farmers do not want to rely on the bank & 72.9 & IV \\
\hline
\end{tabular}

MPS=Mean per cent score, $n=$ Size of sample for beneficiaries

Table.3 Level of social constraints perceived by KCC farmers

\begin{tabular}{|c|c|c|c|}
\multicolumn{2}{|c}{} & \multicolumn{2}{c|}{$\mathrm{N}=75$} \\
\hline S. No. & Aspect & MPS & Rank \\
\hline $\mathbf{1 .}$ & Lack of support of family members & 36.4 & V \\
\hline $\mathbf{2 .}$ & Poor contacts with officers & 83.6 & II \\
\hline $\mathbf{3 .}$ & Traditional society & 76.4 & III \\
\hline $\mathbf{4 .}$ & Illiteracy in the society & 92.4 & I \\
\hline $\mathbf{5 .}$ & The loan does not meet their real credit need & 59.6 & IV \\
\hline
\end{tabular}

MPS=Mean per cent score, $\mathrm{n}=$ Size of sample for beneficiaries

Table.4 Level of miscellaneous constraints perceived by KCC farmers

\begin{tabular}{|c|c|c|c|}
\hline \multicolumn{2}{|c}{} & \multicolumn{2}{c|}{ N $=75$} \\
\hline S. No. & Aspect & MPS & Rank \\
\hline $\mathbf{1 .}$ & Lengthy paper work & 97.8 & I \\
\hline $\mathbf{2 .}$ & Unavailability of communication network & 79.1 & III \\
\hline $\mathbf{3 .}$ & Difficulty in opening bank account & 67.6 & V \\
\hline $\mathbf{4 .}$ & Upgraded to an ATM kisan card & 73.3 & IV \\
\hline $\mathbf{5 .}$ & Illiteracy of farmers leads to various difficulties in understanding of & 83.1 & II \\
\hline $\mathbf{6 .}$ & KCC scheme & 58.2 & VI \\
\hline
\end{tabular}

MPS=Mean per cent score, $n=$ Size of sample for beneficiaries

Table.5 Overall constraints being faced by the KCC farmers

\begin{tabular}{|c|c|c|c|}
\hline S.No. & Constraints & MPS & Rank \\
\hline 1. & Technical & 70.4 & 1ll \\
\hline $\mathbf{2 .}$ & Economical & 74.7 & 11 \\
\hline $\mathbf{3 .}$ & Social & 69.7 & IV \\
\hline $\mathbf{4 .}$ & General & 80.2 & 1 \\
\hline
\end{tabular}

MPS= Mean per cent score, figure within the parentheses are percentage to the total, $n=$ total size of sample

Table 5 continually exposes the next and last major constraint that is social. Majority of the total respondents 69.7 MPS were have forth rank observed from most severe category. It can be concluded from the above findings that the general constraints in deriving the 
benefits of $\mathrm{KCC}$ were the major constraints as felt by 80.2 MPS of KCC holders followed by economical, technical and social constraints, particularly low knowledge of banking system, sub- division and fragmentation of landholding, illiteracy in the society and lengthy paper work were the severest constraints confronted by the KCC holders in having the benefits of the scheme.

With regards to suggestions for making the KCC scheme more effective, it has been suggested that loan amount must be raised from 3 lakhs to 6 lakhs at 4 per cent rate of interest, facility of drawing cash at any branch in the district, the $\mathrm{KCC}$ must be provided to all the farmers, it must be $1^{\text {st }}$ choice for small and marginal farmer and other scheme must be merged in $\mathrm{KCC}$.

\section{References}

Mehrotra, S. and Mathur, S. (2006). Growth of institutional credit. Kurukshetra, 54(11): 23-24.
Mohan, R. (2006). Agricultural credit in India: status, issues and future agenda, Financing Agric. 3-16.

Shukla, A. N. Tewari, S. K. and Dubey, P. P. (2010). "Agricultural credit recovery performance of scheduled commercial banks". Agricultural Science Digest, 30(2):85-89.

Sidhu, R.S. and Gill, S. (2006). Agricultural credit and indebtedness in India: some issues, Indian Journal of Agriculture Economics, 61: 11-35.

Thakur, A. and Barman, U. (2013). "Reasons for poor performance of disbursement of Kishan Credit Card and recovery of loan under the scheme in Assam-A qualitative study". Journal of academia and Industrial Research (JAIR), 2(1): 16-20.

Yasir Mehmood Mukhtar Ahmad Anjum, M. B. (2012). "Factors affecting delay in repayments of agricultural credit; a case study of district Kasur of Punjab province". World Applied Sciences Journal, 2012. 17(4): 447-451.

\section{How to cite this article:}

Amit Kumar Keshri. 2021. Constraints being Faced by the KCC Farmers in Bikaner District of Rajasthan. Int.J.Curr.Microbiol.App.Sci. 10(02): 1460-1464.

doi: https://doi.org/10.20546/ijcmas.2021.1002.175 